\title{
Modeling of strain localization around the radioactive waste disposal galleries
}

\author{
F. Salehnia, R. Charlier \& S. Levasseur \\ Departement ArGenCo, Université de Liège, Liège, Belgium
}

\begin{abstract}
The excavation process of the underground repository galleries creates an Excavation Damaged Zone (EDZ) in which the properties of the host media are locally altered. Since the development of shear bands has been observed during the excavation of underground research facilities in potential clay host rocks, it is proposed here to model the extension of damaged zone by the strain localization approach. Numerical modeling of strain localization needs a specific approach to overcome the practical problem of mesh size dependency within the framework of classical finite elements. To overcome this problem, the second gradient method which has been incorporated into the finite element code Lagamine is proposed in this paper. The objective of this study is to perform the hydro-mechanical modeling of a gallery excavation in Boom Clay (Belgium) accomplished by the analysis of strain localization in shear bands mode: the thickness and evolution of EDZ during the gallery excavation are exhibited through the analysis of plastic zone and increment of deviatoric strain.
\end{abstract}

\section{INTRODUCTION}

Radioactive waste is an inevitable outcome of various industrial and medical activities, such as material testing, manufacturing of some semi-conductors, radiotherapy, food sterilization and electricity production. Nuclear power can be quantitatively an important contributor to the global electricity production capacity. Based on the World Nuclear Association's announcement, nuclear power supplies about $13-14 \%$ of the world's electricity requirements. However, it produces some amount of potentially highly hazardous waste which needs to be carefully managed. In fact, some of the nuclear wastes will remain hazardous to man and the environment for hundreds of thousands of years and should thus be isolated for a long period of time.

There is an international consensus on the advisability of storing high-level nuclear waste in deep geological repository. The depth of a repository (several hundreds of meters) should ensure isolation from the biosphere, while host rock characteristics such as a low permeability should ensure that in the event of a loss of containment due to the degradation of the engineered barrier system, radionuclide releases' rates will remain limited.

The north-east of Belgium is characterized by a thick deposit of over-consolidated marine clay which is known as Boom Clay. Clays are considered as possible hosts for geological disposal systems because of their low permeability, large retention (sorption) capacity for many radionuclides and their self-sealing capacity. Boom Clay is present in Belgium in a region with no volcanic activity and only low seismic activity.

Underground excavation in deep geological host rocks inevitably induces a stress redistribution which results in the creation of a zone with significant irreversible deformations and changes of hydromechanical properties; it is named as Excavation Damaged Zone (EDZ). As the rock is damaged, crack networks are created, which could constitute preferential flow paths, depending on the network connectivity. Consequently, the rock's hydraulic conductivity can be increased significantly and it may become heterogeneous and anisotropic (Shao et al. 2005, Levasseur et al. 2010), although depending on the host rock material, some self-sealing may develop after the excavation. Therefore, the numerical modeling of the extension of the damaged zone and the evolution of its permeability remains important for building confidence in the long-term safety of high-level radioactive waste repositories.

Based on the experimental observations in geomaterials, there is either the localized rupture (Lenoir et al. 2007) due to the localized micro-crack propagation or the diffuse mode of failure (Levasseur et al. 2013). Considering the first phenomenon, strain localization can be mostly observed in shear band mode leading to rupture in geomaterials. Thus the development of strain localization as a classical mode of failure of geomaterials can be studied in order to modelize the extension of EDZ and the fracturing structure. 


\section{NUMERICAL MODELING OF STRAIN LOCALIZATION}

\subsection{First gradient law}

The Drucker-Prager yield surface (Equation 1) in the framework of a frictional elasto-plastic model is used as the constitutive mechanical law:

$F=I_{\hat{\sigma}}+m\left(I_{\sigma}-\frac{3 c}{\tan \phi_{c}}\right)=0$

where $c=$ cohesion; $\varphi_{c}=$ compression friction angle; the first stress invariant, $I_{\sigma}=\sigma_{i j} \delta_{i j}$; the second deviatoric stress invariant, $I I_{\sigma}$, is defined by Equation 3 in which $\hat{\sigma}_{i j}=$ deviatoric stress tensor; and $m$ is given as the following (Equation 2):

$m=\frac{2 \sin \phi_{c}}{\sqrt{3}\left(3-\sin \phi_{c}\right)}$

$I_{\hat{\sigma}}=\sqrt{\frac{1}{2} \hat{\sigma}_{i j} \hat{\sigma}_{i j}}, \hat{\sigma}_{i j}=\sigma_{i j}-\frac{I_{\sigma}}{3} \delta_{i j}$

The friction angle and/or cohesion hardening and/or softening can be occurred as a function of Von Mises equivalent plastic strain (Equation 4):

$\varepsilon_{e q}^{P}=\sqrt{\frac{2}{3} \varepsilon_{i j}^{\hat{P}} \varepsilon_{i j}^{\hat{P}}}$

where hyperbolic functions are used as Equations 5-8:

$i f \varepsilon_{e q}^{P} \prec d e \phi_{\phi}: \phi_{c}=\phi_{c 0}$

$i f \varepsilon_{e q}^{P} \succ d e c_{\phi}: \phi_{c}=\phi_{c 0}+\frac{\phi_{c f}-\phi_{c 0}\left(\varepsilon_{e q}^{P}-d e c_{\phi}\right)}{B_{\phi}+\left(\varepsilon_{e q}^{P}-d e c_{\phi}\right)}$

$i f \varepsilon_{e q}^{P} \prec d e c: c=c$

$i f \varepsilon_{e q}^{P} \succ d e c ; c=c_{0}+\frac{c_{f}-c_{0}\left(\varepsilon_{e q}^{P}-d e c\right)}{B_{c}+\left(\varepsilon_{e q}^{P}-d e c_{c}\right)}$

where $\varphi_{c 0}=$ initial compression friction angle; $\varphi_{c f}=$ final compression friction angle; $c_{0}=$ initial cohesion; $c_{f}=$ final cohesion; $\operatorname{dec}_{\varphi} / \operatorname{dec}_{c}=$ values of equivalent plastic strain from which hardening/ softening starts; and $B_{\varphi} / B_{c}=$ values of equivalent plastic strain for which half of hardening/softening on friction angle and cohesion is achieved (Fig. 1) (Barnichon, 1998).

\subsection{Second gradient law}

Since numerical modeling of strain localization using the classical finite element is depending on the mesh

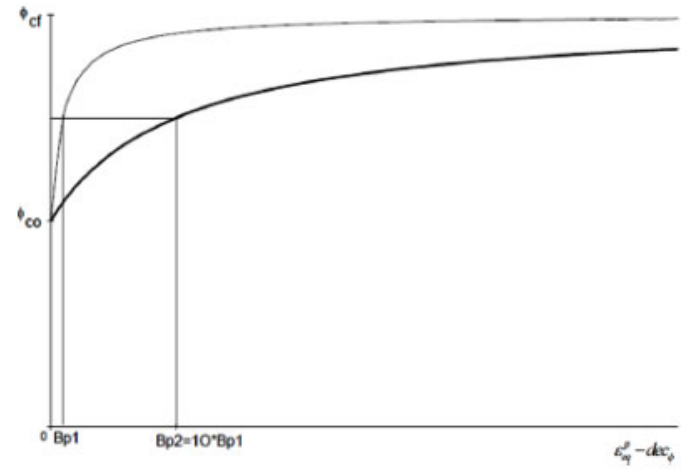

Figure 1. Hardening hyperbolic relation for two values of cofficient $\mathrm{B}_{\phi}$.

size and orientation (Collin et al. 2009), a specific approach is needed to overcome this problem in order to properly model the localization phenomenon and post-peak behavior. Among the different technics, the second gradient model (Chambon et al. 1998 \& 2001) which is a model with internal length is used as the regularization method. The continuum is enriched by microstructure effects in the second gradient method; so the kinematics includes macrokinematics as well as microkinematics (Mindlin 1964, Germain 1973, Collin et al., 2006).

Equations 9-10 are two balance equations (in the weak form) which should be solved in the coupled second gradient model for every kinematically admissible virtual displacement field $u_{i}^{*}$ and virtual pore water pressure field $p_{w}^{*}$ :

$$
\begin{aligned}
& \int\left(\sigma_{i j} \frac{\partial u_{i}^{*}}{\partial x_{i}}+\sum_{i j k} \frac{\partial^{2} u_{i}^{*}}{\partial x_{i} \partial x_{k}}\right) d \Omega=\int_{\Omega} G_{i} u_{i}^{*} d \Omega+\int_{\Gamma_{\sigma}}\left(\bar{t}_{i i} u_{i}^{*}+\bar{T}_{i} D u_{i}^{*}\right) / \Gamma \\
& \int_{\Omega}\left(\dot{M} p_{w}^{*}-m_{i} \frac{\partial p_{w}^{*}}{\partial x_{i}}\right) d \Omega=\int_{\Omega} Q p_{w}^{*} d \Omega+\int_{\Gamma_{q}} \bar{q} p_{w}^{*} d \Gamma
\end{aligned}
$$

where $\Omega=$ current solid configuration (volume); $\Sigma_{i j k}=$ double stress, dual of the (micro) second gradient, which needs an additional constitutive law, and it has no link with the pore water pressure; $G_{i}=$ body force per unit volume; $\bar{t}_{i}=$ external traction (classical) forces per unit area; $\bar{T}_{i}=$ an additional external (double) force per unit area that both $t_{i}$ and $T_{i}$ applied on a part $\Gamma_{\sigma}$ of the boundary of $\Omega ; D u_{i}^{*}$ is the normal derivative of $u_{i}^{*} ; \dot{M}=$ time derivative of the water mass inside $\Omega ; m_{i}=$ mass flow; $Q=$ a sink term; $\Gamma_{q}=$ part of the boundary where the input water mass per unit area $q$ is prescribed; and $\sigma_{i j}=$ the total stress field which is defined according to Bishop \& Terzaghi's postulate as Equation 11:

$\sigma_{i j}=\sigma_{i j}^{\prime}-S_{r, w} p_{w} \delta_{i j}$

where $\sigma_{i j}^{\prime}=$ effective stress; $S_{r, w}=$ water saturation degree; and $\delta_{i j}=$ the Kronecker symbol. 


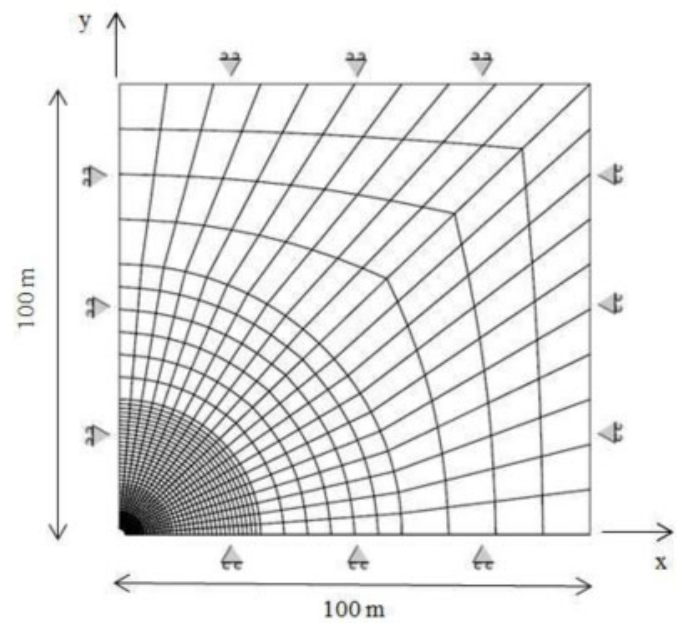

Figure 2. Geometry of the model.

$\Sigma_{i j k}$ in the second gradient law is defined with an elastic law (Mindlin, 1964) as a function of (micro) second gradient of the virtual displacement. It depends on one elastic parameter $\mathrm{D}$ that the shear band width is proportional to this elastic parameter (Chambon et al. 1998 \& Kotronis et al. 2007).

\section{RESULTS OF NUMERICAL SIMULATIONS OF A GALLERY EXCAVATION}

A two-dimensional hydro-mechanical modeling of a gallery excavation has been performed in the plain strain condition using the Finite Element code, Lagamine, from the Université de Liège.

The studied gallery is a synthetic case defined by analogy with one of the principle galleries excavated in the underground research laboratory (URL) close to the city of Mol, Belgium, in order to study the feasibility of high-level nuclear waste disposal in the Boom Clay layer. In fact, the following computed results estimate the evolution of EDZ around this gallery through the shear band analysis. However, this study is now limited to the numerical modeling with no comparison with the field tests' results.

\subsection{Geometry and initial conditions}

Figure 2 shows the two-dimensional mesh geometry of the model. Due to the symmetry of gallery, only a quarter of it has been modeled with a radius of $1.25 \mathrm{~m}$.

The blocked displacements can be observed in Figure 2. The anisotropic initial stresses were applied as $\sigma_{y y}=4.5 \mathrm{MPa}$ and $\sigma_{x x}=\sigma_{z z}=3.825 \mathrm{MPa}$ which were decreased to $100 \mathrm{KPa}$ on the gallery wall during the excavation phase ( 24 hours) and remained constant until the end of simulation ( 3.5 years). Moreover, The initial pore water pressure was equal to $2.25 \mathrm{MPa}$. The other boundries were assumed to be imprevious.
Table 1. Mechanical parameters of model.

\begin{tabular}{llll}
\hline Parameter & Symbol & Value & Unit \\
\hline Young modulus & $\mathrm{E}$ & 300 & $\mathrm{MPa}$ \\
Poisson ratio & $v$ & 0.125 & - \\
Specific mass & $\rho$ & 2700 & $\mathrm{Kg} / \mathrm{m}^{3}$ \\
$\begin{array}{l}\text { Initial friction angle } \\
\text { Final friction angle }\end{array}$ & $\Phi_{0}$ & 8 & $\circ$ \\
$\begin{array}{l}\text { Hardening/softening } \\
\text { coefficient }\end{array}$ & $\mathrm{B}_{\phi}$ & 18 & $\circ$ \\
$\begin{array}{l}\text { Initial cohesion } \\
\text { Final cohesion }\end{array}$ & $\mathrm{c}_{0}$ & 0.001 & - \\
$\begin{array}{l}\text { Hardening/softening } \\
\text { coefficient }\end{array}$ & $\mathrm{c}_{\mathrm{f}}$ & 300 & $\mathrm{BPa}$ \\
$\begin{array}{l}\text { Dilatancy angle } \\
\text { c }\end{array}$ & $\Psi$ & 0.01 & $\mathrm{kPa}$ \\
\end{tabular}

Table 2. Hydraulic parameters of model.

\begin{tabular}{llll}
\hline Parameter & Symbol & Value & Unit \\
\hline Water permeability & $\mathrm{k}_{w}$ & $310^{-19}$ & $\mathrm{~m}^{2}$ \\
Specific mass of water & $\rho_{w}$ & $110^{3}$ & $\mathrm{Kg} / \mathrm{m}^{3}$ \\
Porosity & $\varphi$ & 0.39 & - \\
Water compressibility & $1 / \chi_{w}$ & $510^{-10}$ & $\mathrm{~Pa}^{-1}$ \\
Van Genuchten parameter* & $\mathrm{m}$ & 0.32 & - \\
Van Genuchten parameter* & $\mathrm{n}$ & 1.47 & - \\
Van Genuchten parameter* & $\mathrm{P}$ & 3.44 & $\mathrm{MPa}$
\end{tabular}

*Water retention curve and water permeability based on the Van Genuchten model (Van Genuchten, 1980).

\subsection{Hydro-mechanical properties}

Considering the initial conditions brought in the last section, the model has been analyzed using a frictional elasto-plastic model with the Drucker-Prager yield surface (first gradient law) and the second gradient method; the cohesion softening and friction angle hardening were applied. The applied flow model lets reproducing the existed transfers in porous media.

Tables 1-2 show the hydraulic and mechanical parameters for Boom Clay which were used in the gallery excavation modeling. However, several calculations were performed in the framework of parametric study in which the influences of some parameters of Table 1 were carefully studied; so the brought value of final cohesion will be more explained in the next section based on the fact of considering the cohesion softening.

\subsection{Results}

\subsubsection{Parametric study}

In order to understand precisely about the influences of the main mechanical parameters on strain localization phenomenon, several calculations have been performed including the influence of cohesion softening (parameters $c_{f}$ and $B_{c}$ ) and secondgradient 


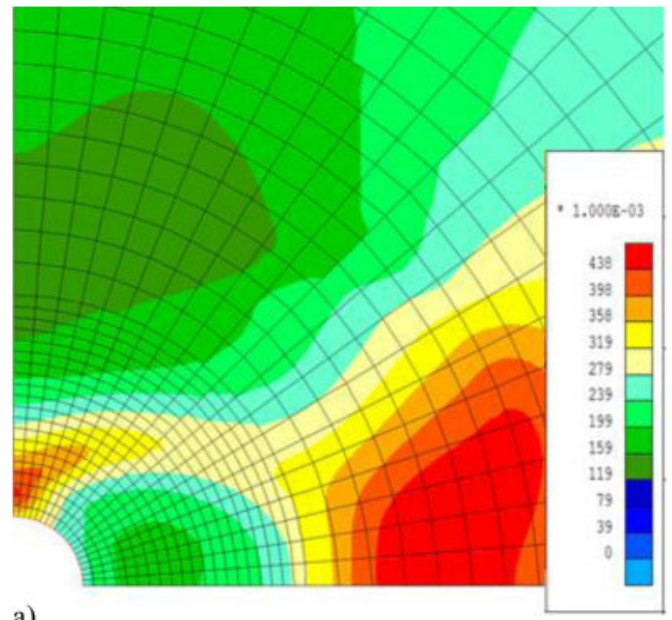

a)

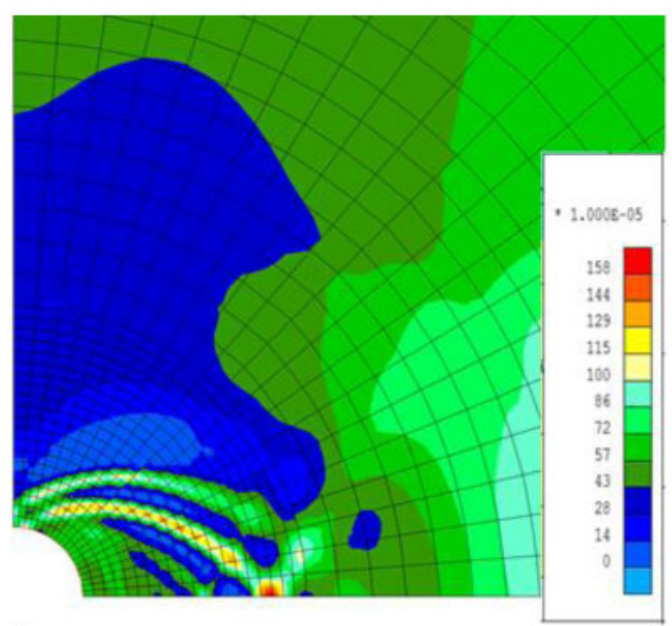

b)

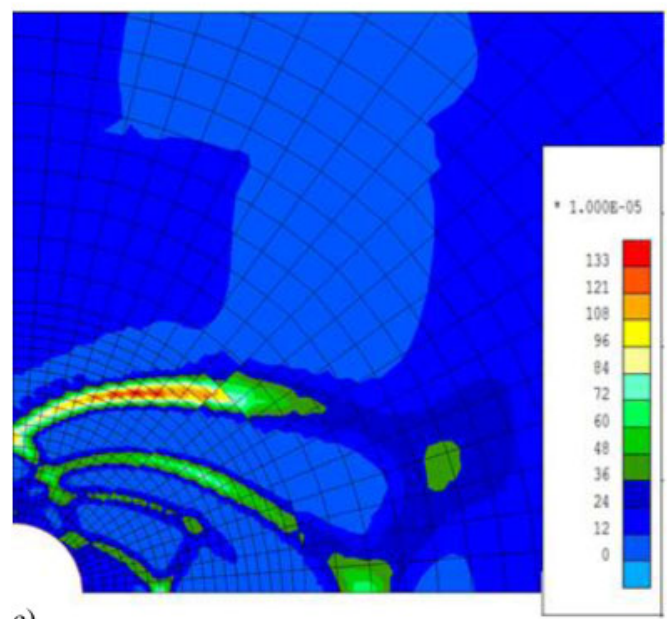

c)

Figure 3. Increment of deviatoric strain as long as the evolution of strain localization after a) 1 day of excavation phase; b) 10 days and; c) 1277.5 days $=3.5$ years, influence of second gradient elastic modulus, $\mathrm{D}=0.2 \mathrm{~N}$.

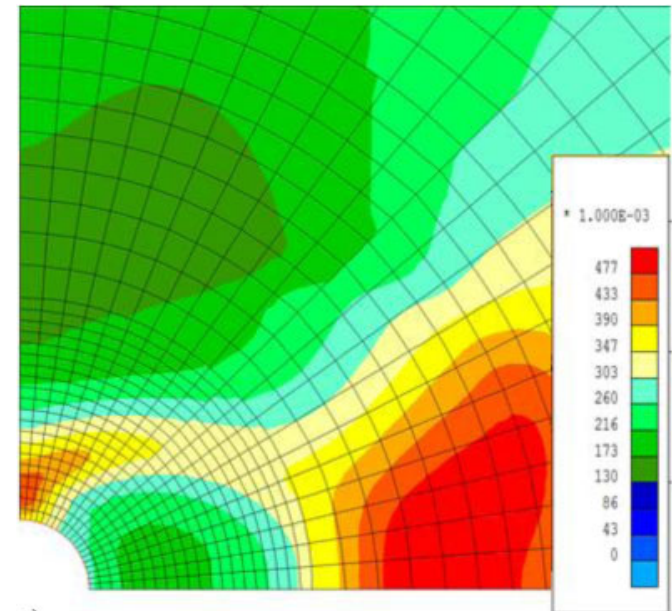

a)

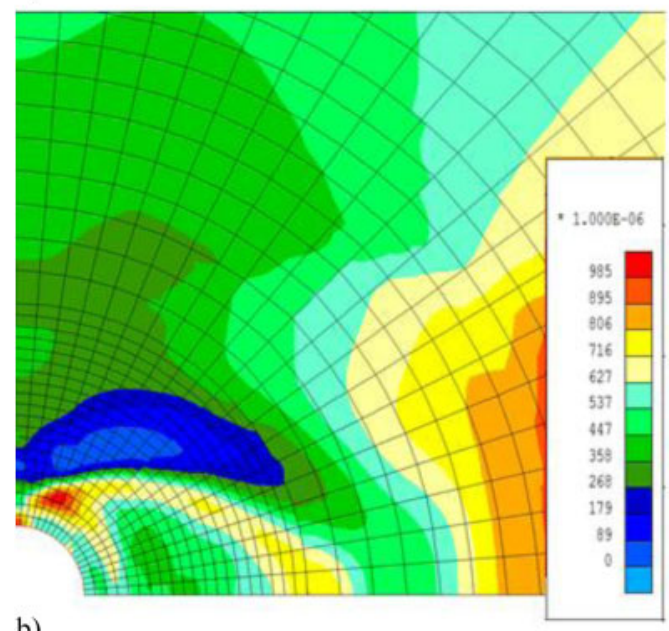

b)

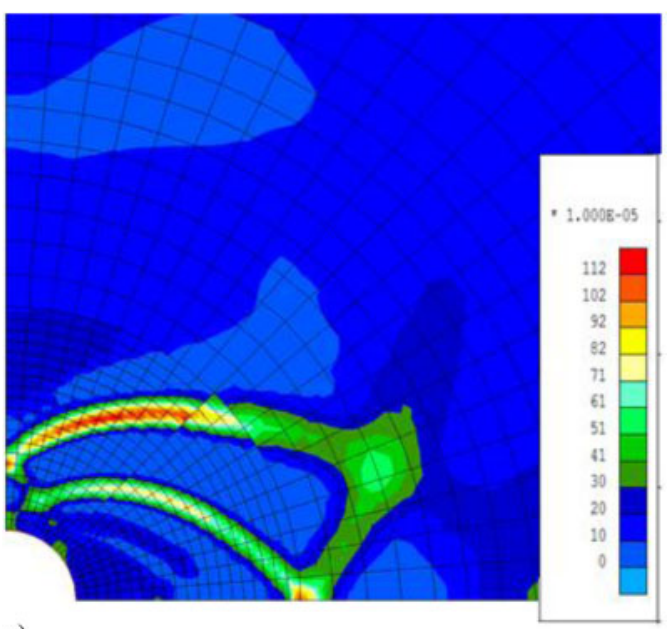

c)

Figure 4. Increment of deviatoric strain as long as the evolution of strain localization after a) 1 day of excavation phase; b) 10 days and; c) 1277.5 days $=3.5$ years, influence of second gradient elastic modulus, $\mathrm{D}=2000 \mathrm{~N}$. 
elastic modulus D. In this paper, it is presented only the influences of second gradient elastic modulus (D) which needs to be obtained numerically since the experimental works cannot give it.

As the consequence, the second gradient parameter affects significantly on the width of the shear strain localization bands. Using the parameters of Tables 1-2 (except of final cohesion which was taken as $c_{f}=200 \mathrm{kPa}$ ), Figures 3-4 show the Increment of deviatoric strain in three different time steps during the calculation (after one day of excavation phase, 10 days, and 3.5 years that is the end of simulation) for two values of $\mathrm{D}$. The smaller second gradient modulus (and implicitly the internal length) as it is observed in Figures 3(b)-4(b) makes larger the apparent softening effect on launching the localization. Moreover Figures 3(c)-4(c) show that increasing the second gradient parameter induces the wider bands of localization. Therefore, the value of $\mathrm{D}$ should be carefully
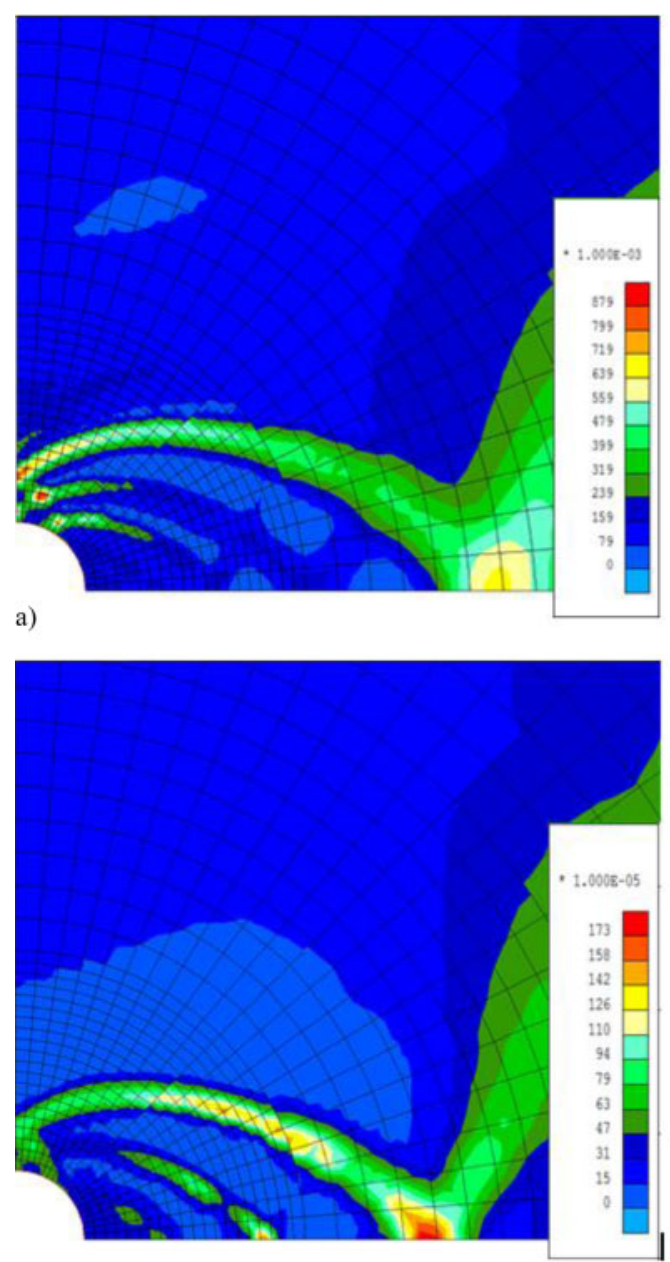

b) chosen considering the mesh element size and it is considered here as $D=2000 \mathrm{~N}$ which seems suitable.

Similarly, the numerical simulations have shown the role of the cohesion softening in order to initiate the strain localization around the gallery. So based on these results, the initial cohesion was divided by factor 10 to give the final cohesion as it was brought in Table 1.

\subsubsection{Study of strain localization pattern}

Taking into account the results of the parametric study, the calculation has been done with the second gradient elastic modulus $D=2000 \mathrm{~N}$ as well as the parameters of Table 1-2.

The results of increment of the deviatoric strain and plasticity of the elements in four different time steps during the calculation (after one day of excavation phase, 100 days, 500 days and 3.5 years that is the end of simulation) are brought in Figures 5-6.

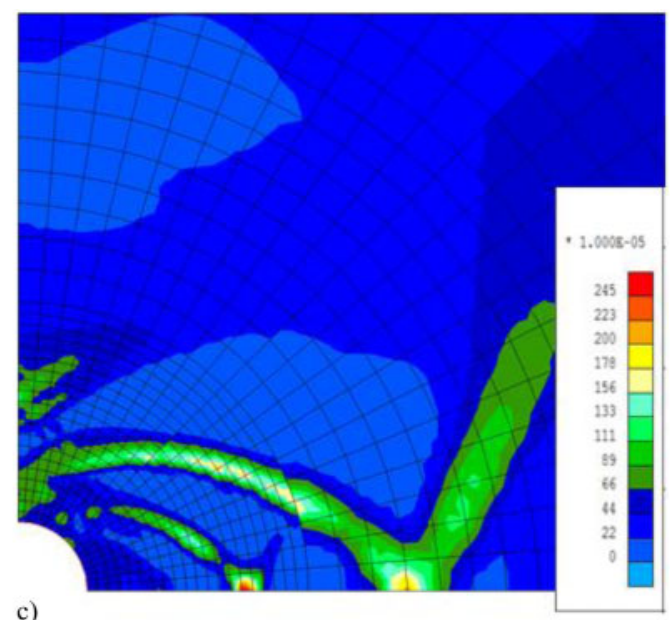

c)

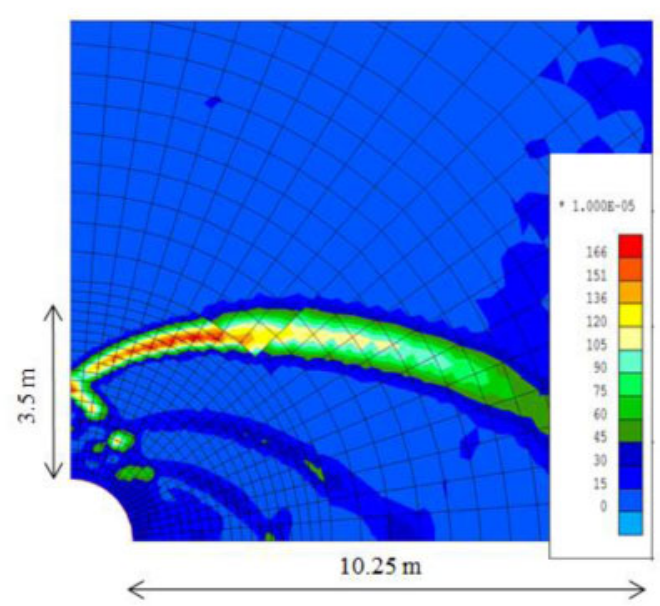

d)

Figure 5. Increment of deviatoric strain as long as the evolution of strain localization after a) 1 day of excavation phase; b) 100 days; c) 500 days and; d) 1277.5 days $=3.5$ years. 


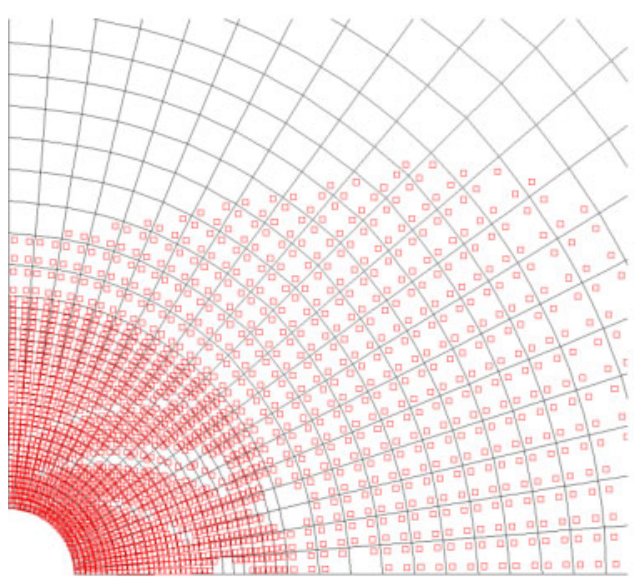

a)

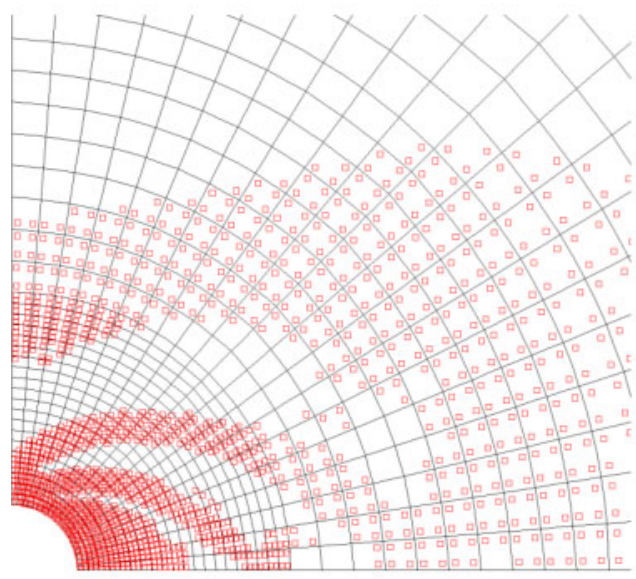

b)

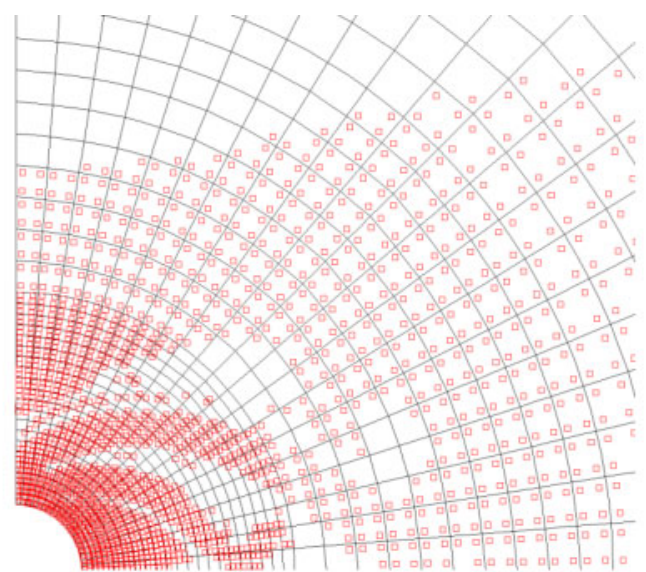

c)

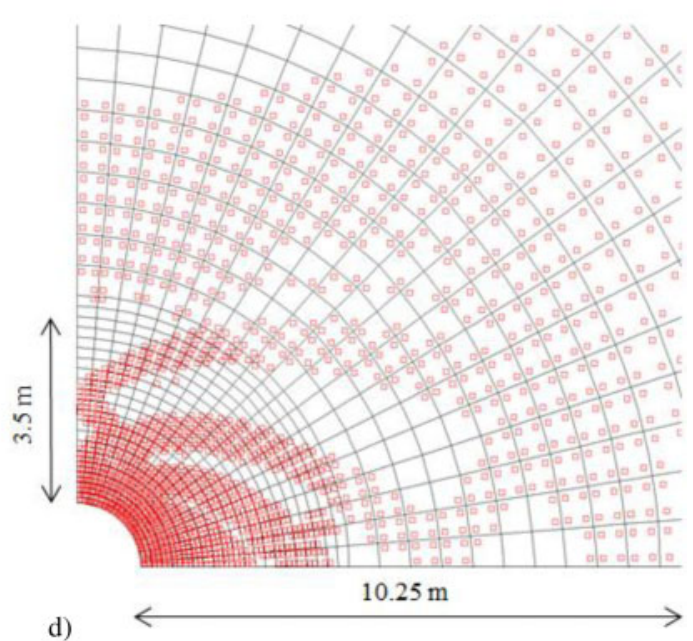

Figure 6. Plasticity as long as the evolution of strain localization after a) 1 day of excavation phase; b) 100 days; c) 500 days and; d) 1277.5 days $=3.5$ years.

In term of the excavation damaged zone, finally the extension of the damaged zone is as $10.25 \mathrm{~m}$ horizontally and $3.5 \mathrm{~m}$ vertically (the coordinate of $11.5 \mathrm{~m}$ horizontally and $4.75 \mathrm{~m}$ vertically) for which the effect of initial anisotropic stress is obvious. The modeling provides some information about the fracturing structure and its evolution, although it still should go beyond some limitations in order to consider the rock properties changes and anisotropic permeability during the localization.

Figure 7 shows three studied cross-sections (horizontal, 45 degree and vertical) around the gallery for which the evolutions of displacements and pore water pressure have been studied.

Evolution of pore water pressure and displacements for the mentioned cross-sections at different times during the simulation (from 1 day which is end of excavation until 1277.5 days $=3.5$ years which is end of calculation) are observed in Figures 8-9. As it was already expected, appearance of the bands of

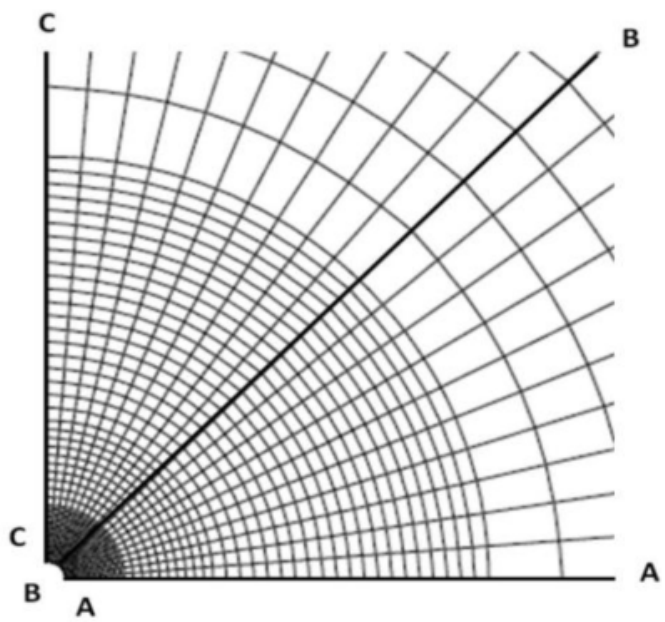

Figure 7. The studied cross-sections. 


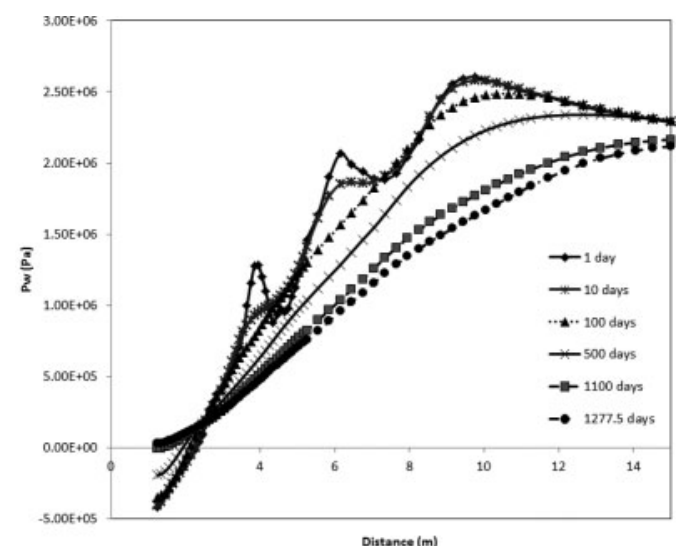

a)

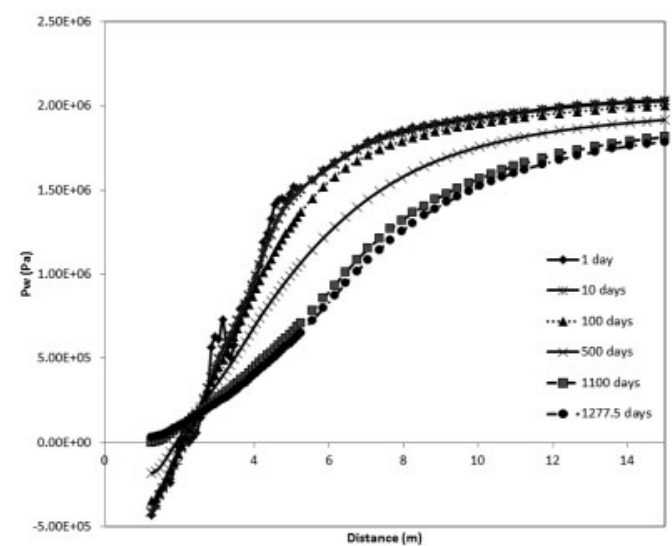

b)

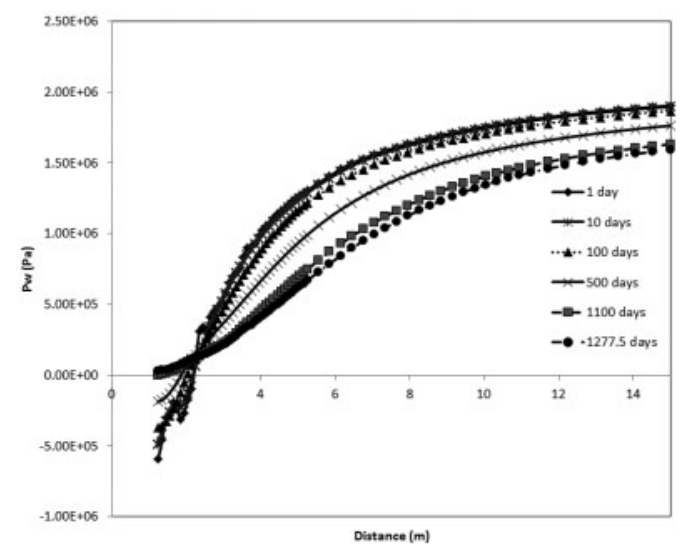

c)

Figure 8. Evolution of pore water pressure for a) horizontal cross-section A-A; b) 45? inclined cross-section B-B and; c) vertical cross-section $\mathrm{C}-\mathrm{C}$.

localization and its development influence clearly in the evolution of pore water pressure (Figure 8) and displacements (Figure 9) with some falls and rises in the pattern of their evolution.

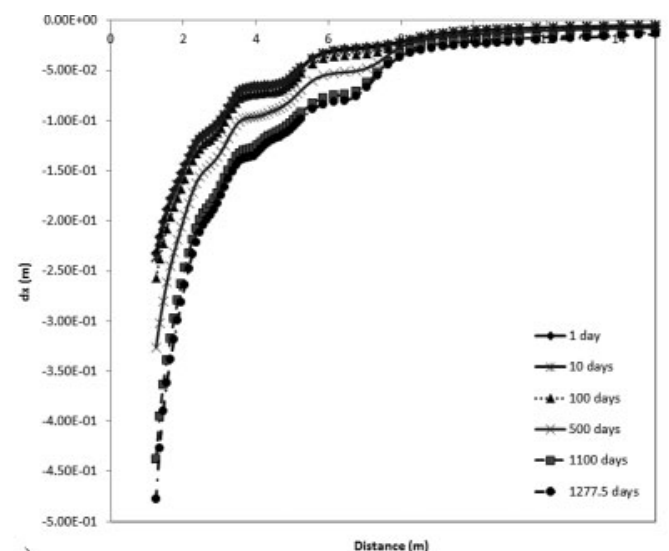

a)

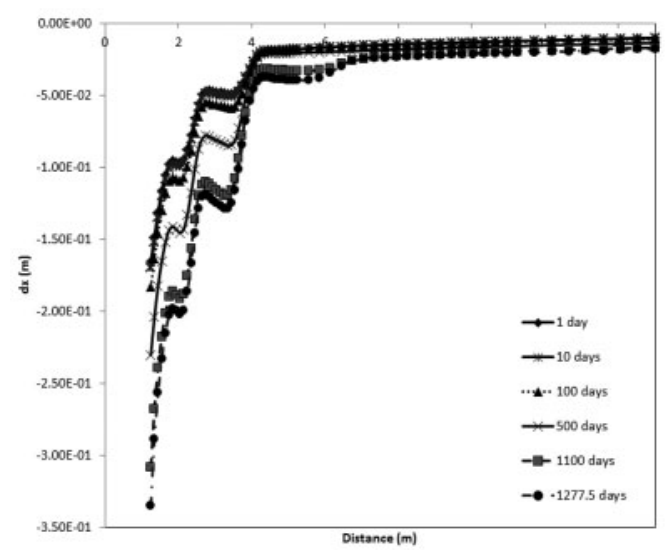

b)

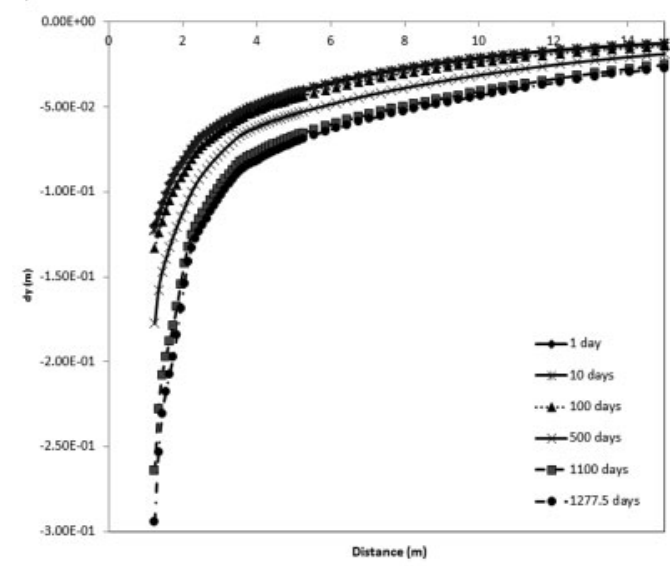

c)

Figure 9. Evolution of displacement of a) $d x$ for the horizontal cross-section A-A; b) dx for the $45^{\circ}$ inclined cross-section $\mathrm{B}-\mathrm{B}$; c) dy for the $45^{\circ}$ inclined cross-section B-B and; d) dy for the vertical cross-section $\mathrm{C}-\mathrm{C}$.

\section{CONCLUSIONS}

Boom clay is considered as a potential host rock formation for the deep geological disposal of high-level 


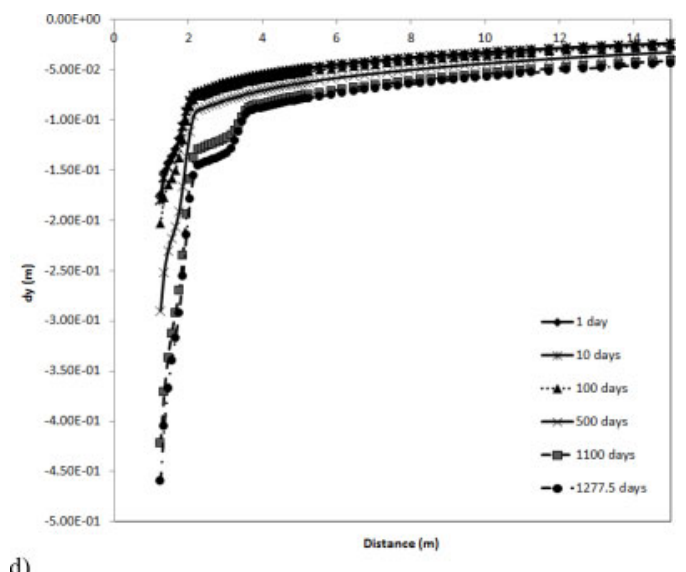

d)

Figure 9. Continued

radioactive waste in Belgium due to its favorable properties, among which its very low hydraulic conductivity. As the creation of an Excavated Damaged Zone (EDZ) around the galleries is inevitable, this permeability will be locally increased during the excavation, while some self-sealing occurs afterwards. Modeling the development of strain localization bands may allow a better estimation of evolution of the hydraulic conductivity in the EDZ. In other words, studying the evolution of fracture network in the framework of strain localization subsequent to rock's damage permits a better understanding of the rock's hydraulic conductivity changes.

The excavation damaged zone and strain localization bands during the excavation phase of a gallery at Mol (Belgium) have been modeled realistically using the second gradient model (Chambon et al. 1998 \& 2001). The results simulated the evolution of the localization bands and the extension of EDZ as $10.25 \mathrm{~m}$ horizontally and $3.5 \mathrm{~m}$ vertically. As it was observed, the effect of strain localization is obvious in terms of evolution of pore water pressure and displacements. Moreover, modeling confirms that permeability is not anymore homogeneous in the damaged zone and it is changed within the shear bands; this phenomenon will be focused in a future study.

\section{ACKNOWLEDGEMENT}

The authors would like to thank the Belgian Agency for Radioactive Waste ONDRAF/NIRAS for their financial support in this project.

\section{REFERENCES}

Barnichon, J.D. 1998. Finite element modeling in structural and petroleum geology: PhD thesis. Liège: Université de Liège.

Chambon, R., Caillerie, D. \& El Hassan, N. 1998. Onedimensional localisation studied with a second grade model. Eur. J. Mech. A/Solids 17(4): 637-656.

Chambon, R., Caillerie, D. \& Matsushima, T. 2001. Plastic continuum with microstructure, local second gradient theories for geomaterials: localization studies. International Journal of Solids and Structures 38: 8503-8527.

Charlier, R. et al. 2010. Thermal impact on the damaged zone around a radioactive waste disposal in clay host rocks. European commission.

Collin, F., Chambon, R. \& Charlier R. 2006. A finite element method for poro mechanical modelling of geotechnical problems using local second gradient models. Int. J. Numer. Meth. Eng. 65 (11): 1749-1772.

Collin, F., Levasseur, S. \& Chambon, R. 2009. Numerical post failure methods in multiphysical problems. Eur. $J$. Environ. Civ. Eng 13(7-8): 983-1004.

Germain, P. 1973. The method of virtual power in continuum mechanics. Part 2: Microstructure. SIAM J. Appl. Math 25: 556-575.

Kotronis, P., Collin, F., Bésuelle, P., Chambon, R. \& Mazars, J. 2007. Local Second Gradient Models and Damage Mechanics: 1D Post Localization Studies in Concrete Specimens. 7th International Workshop on Bifurcation, Instabilities and Degradation in Geomechanics: 127-142.

Lenoir, N., Bornert, M., Desrues, J., Bésuelle, P. \& Viggiani, G. 2007. Volumetric digital image correlation applied to $\mathrm{X}$-ray microtomography images for triaxial compression tests on argillaceous rock. Strain 43(3): 193-205.

Levasseur, S., Charlier, R., Frieg, B. \& Collin, F. 2010. Hydromechanical modelling of the excavation damaged zone around an underground excavation at Mont Terri Rock Laboratory. Int. J. Rock Mech. Min. 47: 414-425.

Levasseur, S., Collin, F., Charlier, R. \& Kondo, D. 2013. A micro-macro approach of permeability evolution in rocks excavation damaged zones. Comput. Geotech. 49: 245-252.

Mindlin, R.D. 1964. Micro-structure in linear elasticity. Arch. Ration. Mech. Anal. 16: 51-78.

Shao, J.F., Zhou, H. \& Chau, K.T. 2005. Coupling between anisotropic damage and permeability variation in brittle rocks. Int. J. Numer. Anal. Methods Geomech 29:12311247.

Van Genuchten, M. TH. 1980. A closed-form equation for predicting the hydraulic conductivity of unsaturated soils. Soil Sci. Soc. Am. J. 44:892-898.

World Nuclear Association. www.world-nuclear.org. 